\title{
Pricing the global health risks of the COVID-19 pandemic
}

\section{W. Kip Viscusi ${ }^{1}$}

Accepted: 13 October 2020 / Published online: 2 November 2020

(C) Springer Science+Business Media, LLC, part of Springer Nature 2020

\begin{abstract}
Policies to address the coronavirus disease 2019 (COVID-19) require a balancing of the health risk reductions and the costs of economic dislocations. Application of the value of a statistical life (VSL) to monetize COVID-19 deaths produces a U.S. mortality cost estimate of $\$ 1.4$ trillion for deaths in the first half of 2020. This article presents worldwide COVID-19 costs for over 100 countries. The total global mortality cost through July 2, 2020 is $\$ 3.5$ trillion. The United States accounts for $25 \%$ of the deaths, but $41 \%$ of the mortality cost. Adjustments for the shorter life expectancy and lower income of the victims substantially reduces the estimated monetized losses, but may raise fundamental equity concerns. Morbidity effects of COVID-19 affect many more patients than do the disease's mortality risks. Consideration of the morbidity effects increase the expected health losses associated with COVID-19 illnesses by $10 \%$ to $40 \%$.
\end{abstract}

Keywords Coronavirus · COVID-19 · Value of statistical life $\cdot$ VSL $\cdot$ Mortality · Morbidity

JEL Classification $\mathrm{H} 40 \cdot \mathrm{I} 18 \cdot \mathrm{J} 17 \cdot \mathrm{K} 32$

\section{Introduction}

The coronavirus disease 2019 (COVID-19) pandemic has forced countries worldwide to make often difficult tradeoffs between health risks and financial costs. These concerns are not always incompatible. Widespread societal illnesses will have adverse economic repercussions as well. But if a country adopts an aggressive policy to reduce the spread of the pandemic, such as a lockdown or stringent social distancing efforts, on

Robert J. Cramer provided excellent research assistance, and Thomas J. Kniesner provided valuable comments.

W. Kip Viscusi

kip.viscusi@vanderbilt.edu

1 Vanderbilt Law School, 131 21st Ave. South, Nashville, TN 37203, USA 
balance there will be long run economic costs associated with these dislocations. Similarly, attempts to reopen the economy by relaxing the restrictions may produce some economic gains but will also increase the health risks from the additional exposures. To properly assess whether such policies on balance are worthwhile, it is essential to be able to compare the value of the health risks that are reduced with the economic costs of restrictions. This article presents procedures for monetizing the risks of mortality and morbidity associated with COVID-19 and finds that the costs of these mortality risks should loom quite large in any assessment of the desirability of precautionary actions.

The starting point for such an assessment is the economics literature on the value of a statistical life (VSL), which is the individual's local money-mortality risk tradeoff value. The pertinent valuation concept is the value of small changes in risk, not the value attached to identified lives. Conflating these concepts is common. During the early stage of the pandemic, New York Governor Andrew Cuomo made the following claim: "My mother is not expendable. And your mother is not expendable. And our brothers and sisters, they're not expendable....We're not going to put a dollar figure on human life." While this article does not value identified lives, it is feasible to value risks to life consistent with decisions made with respect to other risk-related matters. Following this valuation approach demonstrates the importance of reducing mortality risks and does not devalue these risks.

There is substantial empirical evidence indicating the magnitude of the tradeoff between money and mortality risk based on the preferences of those affected by risks. Empirical evidence on the VSL can be derived from revealed preference evidence on risky decisions by workers or consumers, or by stated preference surveys that elicit valuation amounts for risk reductions (Viscusi 2018b). Applying these values in a straightforward manner is instructive, but there are several fundamental concerns that have arisen with respect to these valuations. The scale of the pandemic and the subsequent economic dislocations are much greater than in many applications of the VSL, which are usually within the context of specific health, safety, and environmental regulations. The general public typically displays sympathy with those who suffer illnesses, particularly when the illnesses are not the result of moral hazard. However, the scale and prominence of the economic costs of this pandemic have sometimes led to questions about whether for pandemics it is appropriate to use the same benefit value for mortality risks that is usually employed. Examples of such queries and attempts to fine tune the VSL are the following. Does COVID-19 primarily affect those who are very old or who have life-threatening pre-existing conditions, and, if so, should we accord them the same VSL as we would for those with a greater remaining life expectancy? Along the same lines, people who are poor and who have limited access to medical care are faring worse in this pandemic. Should their income status enter into the valuation, reducing the value that their lives receive? More generally, does the magnitude of the health threat undermine the application of conventional benefit assessment approaches?

While the primary focus of public health officials' pronouncements has been on identified positive tests of COVID-19 and the associated mortality rate, most COVID-

\footnotetext{
${ }^{1}$ Statement by Andrew Cuomo, quoted in "NY Governor on Conservatives Who Want to End Social Distancing: Life Is Not Disposable," HuffPost, March 24, 2020, and Associated Press, March 26, 2020.
} 
19 victims do not die. However, many of them do suffer consequential morbidity effects. How should the valuation of these morbidity impacts be conceptualized? Are there sensible reference points for assessing the value of reducing these risks? Based on the estimated value of these health losses, is it important to consider both the mortality and morbidity effects of COVID-19?

To provide a sense of the enormity of this pandemic, Section 2 provides a brief overview of the scale of the health impacts to date. Section 3 focuses on my focal VSL figure of \$11 million in \$2019 for the United States (Viscusi 2018b). What is the basis for selecting a VSL number? Is it appropriate to use it to value mortality risks from COVID-19, given both the level of the risk and the nature of the health impacts? The most prominent resistance to high valuation amounts in the COVID-19 context has stemmed from concerns about the age and the previous health status of those who have died from COVID-19. Section 4 addresses these and other concerns that surface when attempting to personalize the VSL levels to the circumstances of the particular individuals being protected. Section 5 estimates country-specific global mortality costs by applying international VSL estimates that have been derived from the best United States estimates. After adjustments for income differences across countries, it is feasible to calculate the worldwide COVID-19 mortality cost as well as the loss for each affected country. The potentially important role of morbidity effects is the subject of Section 6. The risk of serious nonfatal health consequences merits a substantial economic value, particularly given the greater frequency of morbidity losses than mortality effects of COVID-19. One implication of the concluding Section 7 is that monetizing the health risks of this pandemic does not require that we jettison the established economic approaches to valuing health risks. However, the crisis may enable us to sharpen the policy practices with respect to dealing with these and other such risks in the future.

\section{The dimensions of COVID-19 risks}

Proper conceptualization of the magnitude of the risk from the standpoint of policy decisions requires that one compare the risks that would prevail with and without a policy intervention. Thus, the appropriate matter for benefit assessment is the marginal change in the risk outcome that will be achieved through the policy. Unless the policies involve undertaking no precautions, the risk outcomes that would have prevailed in the absence of the policy will not be observable. Instead, one must estimate the predicted risk levels using infectious disease models that reflect the contagion risk of coronavirus. Among the more prominent such estimates for the United States were that in the absence of restrictive efforts to address the pandemic, there could be potentially 1-2 million deaths. ${ }^{2}$ Benefit-cost analyses of prospective policies have refined these estimates (Thunstrom et al. 2020; Greenstone and Nigam 2020; Robinson, Sullivan, and Shogren 2020). That these figures greatly exceed the observed number of deaths to date does not necessarily imply that the worst-case projections are faulty. What is being

\footnotetext{
${ }^{2}$ See, for example, the CNN story, March 15, 2020, for the statement by Dr. Anthony Fauci, "Possible that millions could die in U.S." https://www.cnn.com/2020/03/15/politics/anthony-fauci-coronavirus-potentialdeaths/index.html. Accessed July 13, 2020.
} 
observed are the deaths that occur after precautions have reduced the level of the risk, not the number of deaths that would have occurred if no precautions had been in place.

Although the number of coronavirus cases continues to increase and remains a moving target, the experience with the virus thus far is sufficient to get a general sense of the order of magnitude of the risks. ${ }^{3}$ The magnitude of the positive test results and deaths continues unabated, but considering the statistics at midyear provides an overall sense of the disease impacts that are already substantial. As of July 2, 2020, there were $10,847,011$ coronavirus cases in the world and 2,781,085 cases in the United States, which accounts for $26 \%$ of global cases. Worldwide, the number of cases is 1392 per million population, or a positive coronavirus test risk of just over 1/1000. For the United States, the risk of a positive test per million population is 8402 , or a risk of just under $9 / 1000$. The number of deaths in that time period is 519,888 in the world, with 130,813 in the United States, or 25\% of the global total. The COVID-19 death rate for the population is 66.7 per million for the world and 395 per million in the United States, or under 1/10,000 in the world and just under 4/10,000 in the United States. Each of these risk levels is comparable to various annual occupational fatality risks, which will serve as a reference point for the valuation of policy interventions. Other countries have also incurred substantial risks, such as Brazil with 60,813 deaths, the U.K. with 43,906 deaths, Italy with 34,788 deaths, France with 29,861 deaths, and Spain with 28,363 deaths. There are also some outliers of countries that have undertaken very effective efforts to control the outbreak, notably New Zealand with 22 deaths and Australia with 104 deaths.

The incidence of COVID-19 death risks is not uniform across the population. The risks vary by gender, age, race, pre-existing conditions, and other personal characteristics. The attribute that has received considerable attention to date is the variation in the risk by age. Table 1 summarizes the distribution of COVID-19 deaths in the United States from February 1, 2020, to June 20, 2020 for different age groups. These statistics are averages across the entire population. The gender-specific statistics for men and women appear in Appendix Table 4. In terms of the total number of deaths, it is apparent that the mortality risk escalates quite sharply with age, reaching high values in excess of 10,000 deaths in the age category for all age groups from age 55 and above. As a percentage of all deaths, the age groups beginning with the 45-54 age range each account for at least $5 \%$ of the deaths. Despite the increased more general mortality rate of those in older age groups, which leads to a smaller total population at risk from COVID-19 in these groups, the percentage of all COVID-19 deaths accounted for by COVID-19 risks increases with age, reaching a peak of $33 \%$ for those age 85 or older. This concentration among the very old population groups may diminish over time as the most vulnerable members of this group die and the disease incidence begins to become more prominent among younger age groups.

The fatality rates for the different population groups vary similarly with age. For those age 45-54 or younger, the COVID-19 fatality rate is $1 / 10,000$ or less. The fatality rate for each age group rises steadily with age, reaching a peak of $6 / 1000$ for those age 85 or older. Although these risks are high, they are not outside of the range of risks that are discussed below in studies estimating the VSL for workers facing job risks. This risk level is comparable in magnitude to relatively high risk occupational risk categories

\footnotetext{
${ }_{3}^{3}$ See Worldometer (2020). Statistics are from Worldometers: https://www.worldometers.info/coronavirus.
} 
Table 1 The Age Distribution of COVID-19 Deaths in the United States

\begin{tabular}{llll}
\hline Age group & Number of deaths & Percentage of all deaths & Deaths per 100 population \\
\hline$<5$ & 15 & 0.014 & 0.00008 \\
$5-14$ & 13 & 0.012 & 0.00003 \\
$15-24$ & 132 & 0.122 & 0.00031 \\
$25-34$ & 732 & 0.678 & 0.00162 \\
$35-44$ & 1860 & 1.722 & 0.00453 \\
$45-54$ & 5238 & 4.850 & 0.01287 \\
$55-64$ & 12,895 & 11.940 & 0.03088 \\
$65-74$ & 22,429 & 20.768 & 0.07123 \\
$75-84$ & 28,735 & 26.607 & 0.18651 \\
$85+$ & 35,948 & 33.286 & 0.61001 \\
All ages & 107,997 & 100 & 0.03330 \\
\hline
\end{tabular}

Notes: Data reflect deaths in the United States from February 1, 2020 to June 20, 2020, updated on June 24 CDC (2020): https://data.cdc.gov/NCHS/Provisional-COVID-19-Death-Counts-by-Sex-Age-and-S/9bhghcku

The 2019 age group population data are from U.S. Census Bureau (2020):

https://www.census.gov/data/tables/2019/demo/age-and-sex/2019-age-sex-composition.html

in these samples, including i) transportation and material moving occupations and ii) handlers, equipment cleaners, helpers and laborers, where these occupations are in industries such as mining, construction, and transportation.

\section{The VSL for COVID-19 mortality risks}

The benefit associated with reduced mortality risks comprises the largest component of benefits for health, safety, and environmental regulations generally, so it is not surprising that the value of reduced mortality risks plays a prominent role for COVID-19 as well. Unlike other health impacts, such as nonfatal morbidity effects, measures of fatality risk are well-defined in terms of their severity. Deaths are also comparatively straightforward to monitor, although the presence of multiple adverse health conditions sometimes complicates conclusions regarding causality. Fatalities also represent the gravest adverse health impact so that reducing this risk will have the largest value for any given COVID-19 patient. As a reflection of the greater ability to monitor fatalities, it is noteworthy that the worldwide statistics on coronavirus risks do not include comparable information on morbidity losses among those who do not die.

\subsection{The baseline VSL estimate}

The benefit assessment procedure for valuing mortality risks is well-established. The VSL provides information on the local money-risk tradeoff rate for small increases or decreases in the risk level. There are VSL estimates based on revealed preference data using implicit values in market contexts as well as stated preference values derived 
from surveys on willingness to pay for risk reductions. My emphasis is on labor market estimates of the VSL that are obtained by analyzing the wage premiums that workers receive for occupational fatality risks. There have been over 1000 published labor market estimates of the VSL in this literature, which is reviewed in the meta-analysis in Viscusi (2018a). Because the VSL is not a natural constant but varies with individual preferences and opportunities, there is heterogeneity in the individual VSL levels. Different studies and different samples will lead to different VSL estimates. For most purposes, it is appropriate to rely on the average VSL for workers to value broad reductions in risk across the population. The estimates that are most reliable are the labor market estimates in which the fatality risk values based on the Census of Fatal Occupational Injuries (CFOI) data are matched to workers in the employment sample.

The potential role of publication selection effects in biasing empirical estimates, including those pertaining to the VSL, is well established (Stanley and Doucouliagos 2012). Researchers may choose to submit for publication only those results that are consistent with previous estimates in the literature. Similarly, reviewers and journal editors may be unwilling to publish VSL estimates that are outside of the range reported in previous studies. Adjustments for publication selection effects for the VSL account for such influences and generally result in lower estimated VSL amounts after the bias correction. The focal estimate in Viscusi (2018b) of \$10 million in \$2015 was based on bias-corrected estimates using the CFOI. The genesis of this value was two previous meta-regression analyses of VSL estimates using the CFOI data. Viscusi (2015) reported a VSL estimate of $\$ 9.6$ million in $\$ 2013$, which now has an inflationadjusted value in $\$ 2019$ of $\$ 10.6$ million. The $\$ 9.6$ million bias-adjusted VSL estimate in \$2015 reported in Viscusi and Masterman (2017a and b) has a value in \$2019 of $\$ 10.5$ million. These estimates are derived from meta-regression analyses of the best estimates drawn from particular studies, i.e., the estimates based on the single most preferred estimate in the judgment of the authors or the reviewer of the literature. Alternatively, Viscusi (2018a) derives a bias-adjusted CFOI estimate of the VSL based on the full set of VSL estimates from all CFOI studies rather than the single preferred estimate from each of the studies. Doing so avoids potential biases resulting from the selection of the best estimate, but may have the downside of including less preferred equation specifications. The bias-adjusted estimates, which vary depending on the treatment of the other variables in the analysis, are $\$ 9.6$ million for the sample of all estimates and $\$ 11.4$ million for the sample of best estimates, where these figures are in $\$ 2015$. Converted to $\$ 2019$, the all-set VSL is $\$ 10.4$ million and the best-set value is $\$ 12.4$ million. For purposes of the calculations in this article, I will use a focal United States VSL value of $\$ 11$ million. This value is in the general range as those used by U.S. government agencies. ${ }^{4}$

Other empirical estimates of the VSL are in a similar general range, but are somewhat higher if they are not adjusted for publication selection effects. It is instructive to review some of these values to provide an alternative perspective on the choice of the VSL. The VSL literature review in Viscusi and Aldy (2003) preceded the use of

\footnotetext{
${ }^{4}$ The U.S. Department of Transportation (2016) guidance specifies a VSL of \$9.6 million in \$2016, as did the U.S. Department of Health and Human Services (2016), or an inflation-adjusted value of $\$ 10.2$ million in \$2019. The U.S. Environmental Protection Agency (2016) VSL is \$7.9 million in \$2008, which has an inflation-adjusted value of $\$ 9.7$ million in $\$ 2019$. Agencies may also make other adjustments, such as for rising income levels over time.
} 
the CFOI data and reported a median VSL of \$10.3 million in \$2019. The first VSL estimates using the CFOI were reported in Viscusi (2004) and were \$11.2 million (\$2019) for the male blue-collar sample, which is the principal locus of jobs with fatality risks. The panel data estimates for job changers reported in Kniesner et al. (2012) yielded a VSL of $\$ 9.2$ million based on single years of CFOI data and $\$ 12.8$ million using three-year averages of CFOI data, where all estimates are in \$2019. Although there are numerous other VSL estimates in the literature, the meta-analysis in Viscusi (2018a) is a comprehensive review of these estimates as well as the estimates from other studies. After converting the values to $\$ 2019$, the reported sample mean VSL estimate based on CFOI studies is \$13.2 million for the all-set sample and \$13.3 million for the best-set sample. The $\$ 11$ million VSL figure that I will use for the discussion in this article consequently is about $\$ 2$ million below the mean estimated VSL implied by the CFOI estimates without any adjustment for publication selection effects. Sensitivity analysis for the results below using a $\$ 13$ million figure rather than $\$ 11$ million is straightforward.

\subsection{The income elasticity of the VSL}

Income levels are an important driver of how much people are willing to pay to reduce risks and how much they must be compensated to incur an increase in risk. The VSL varies with income levels across the population within a country, across time for a country with changing income levels, and across countries at different stages of economic development. There is a very large literature on the income elasticity of the VSL, much of which is reviewed in Viscusi and Aldy (2003) and Masterman and Viscusi (2018). The emphasis here is on the income elasticity numbers that will be used for the United States and the international average for countries outside the United States. ${ }^{5}$ For changes in income within the United States, I use an income elasticity figure of 0.6 based on the recent meta-regression analysis in Viscusi and Masterman (2017a and b), which estimates a U.S. income elasticity value between 0.5 and 0.7 . A previous meta-regression analysis by Doucouliagos et al. (2014) accounting for publication selection effects found an income elasticity range from 0.25 to 0.63 . The main use of U.S. income elasticity figures by government agencies has been with respect to updating estimates of the VSL over time to account for increases in societal income levels. However, it could also be used to adjust the VSL to correspond to the income levels of those affected by COVID-19. For international differences, I adopt an income elasticity figure of 1.0. The international unitary income elasticity figure is consistent with the meta-regression analyses of revealed preference labor market data in Viscusi and Masterman (2017a and b), which yielded an income elasticity estimate for which it was not possible to reject the hypothesis that the elasticity is 1.0 in any of the specifications. Similarly, a meta-regression analysis of stated preference data in Masterman and Viscusi (2018) estimated an overall income elasticity of the VSL across countries of 0.94 to 1.05 . I use an international income elasticity of 1.0 in analyzing the worldwide costs of COVID-19. The international income elasticity estimates plays a pivotal role in international analyses presented in Section 5, as it is

\footnotetext{
${ }^{5}$ The international income differences discussed here pertain to a wide set of countries. For discussion of other considerations involved in transferring VSL levels across countries, see Hammitt and Robinson (2011).
} 
used to project the U.S. VSL estimates to other countries based on differences in income levels across the countries.

\subsection{The appropriateness of benefit transfer}

Government agencies have generally adopted VSL estimates from the literature without adjusting for the within-country differences in the income levels of those in the labor market studies and the populations at risk. Because the labor market studies focus on the income levels of workers, the average income level being reflected in these studies is that of the average worker. Based on the meta-analysis of the literature in Viscusi (2018a), the average annual income level is $\$ 41,786$ in the best-set sample and $\$ 46,105$ in the all-set sample in $\$ 2019$, where the all-set sample includes multiple estimates from particular articles. COVID-19 victims with higher income levels than these amounts consequently will have a greater VSL than the worker average, and victims with a lower income will have a lower VSL than the worker average. Workers at the aspirational minimum wage of $\$ 15$ per hour consequently have a VSL that is about $17 \%$ less than the national worker average.

The risk levels reflected in the labor market studies of wage-risk tradeoffs are based on the prevailing occupational risk levels in the labor market. In the early studies in the literature, the average risk level in the sample was 1/10,000. In large part because of the change in the occupational job mix over time as well as improvements in safety, the average risk in the more recent VSL studies is around 1/25,000. Within each sample, there is typically wide variation in the worker risks. Workers in relatively safe industries such as finance, insurance, and real estate face an annual fatality risk of just over $1 / 100,000$, whereas the average risk for the mining industry is $1 / 4000$. Occupations within industries may, of course, face greater risks, such as 1/2000 or more.

For small changes in risk, the VSL implies a local rate of tradeoff that is the same for risk increases and risk decreases. For larger changes in risk, there is some modification of these values. Before indicating the magnitude of these modifications, it is important to first discuss the policy context in which the VSL numbers will be used. The policy impact of the specific policy being discussed is what is pertinent, not the collective impact of all COVID-19 efforts. For individual policy actions such as the decision to reopen restaurants, the banning of sports contests, and requirements that airlines leave the middle seat open, the effect of the policy change has a very small impact on any individual's risk level. Larger risk changes arise when considering global decisions such as whether we should undertake a comprehensive social distancing policy that will greatly reduce the risk. Even within such a broad context, there are usually many component policy decisions generating incremental impacts rather than major shifts in risk level.

Should the policy have a non-incremental impact on risk levels, the estimates presented in Viscusi (2010) using a logarithmic utility function provide an illustrative example of the influence of risk changes of between 1/10,000 and 1/1000. Consider a starting mortality risk value for the population from COVID-19 of $1 / 1000$. Suppose that the particular policy action being considered will reduce the risk from 1/1000 to $1 / 10,000$. Because of the shape of the utility function and the constant expected utility locus that is tangent to the market offer curve, large risk changes do not have the same value as very small local changes in the risk. Viewed from the standpoint of individual 
willingness to pay for risk reductions, when the risk change is very large there are important income effects as individual resources become depleted when purchasing large risk reductions. Then for logarithmic utility functions, the willingness-to-pay (WTP) amount is $8 \%$ less than the VSL would be for small changes in risk. Similarly, for risk increases from $1 / 10,000$ to $1 / 1000$, the willingness-to-accept (WTA) amount is $10 \%$ greater than the VSL. Using a different functional form, Hammitt (2020) also provides evidence of the variation in the valuation of risks with the magnitude of the risk change.

In the most extreme case, the decision to undertake comprehensive precautionary policies rather than no precautions at all may save 1 million lives in the United States, or a risk reduction of just under 1/300. Saving a million lives valued at $\$ 11$ million each has a value of $\$ 11$ trillion if there is not adjustment of the VSL for the magnitude of the risk reduction, overstating society's overall willingness to pay for the risk reduction. Except for such global protection decisions involving the choice of whether to undertake any COVID-19 precautions, most risk changes for policies are small, making the VSL the pertinent number. The policy decisions with respect to reopening particular activities such as salons and dining tend to involve small risks. Even a policy change that will lead to 100,000 additional expected deaths in the United States involves an increased risk probability of $3 / 10,000$, which is comparable to some high-risk jobs, so that no major modifications of the VSL are warranted.

If the policy will produce a non-incremental risk change, whether the VSL overstates or understates the appropriate value depends on the direction of the risk change. If a policy is going to increase the risk level, such as a decision to reopen the economy or to abandon the recommended use of face masks, then the higher WTA values are appropriate. For decisions to reduce the risk by mandating particular precautions, the lower WTP values would be pertinent. In each instance, the pertinent VSL tradeoff rate usually does not diverge much from the VSL except for extreme policy options. These spreads between the WTP and WTA amounts are driven by the shape of the utility functions, not irrational responses to increases in risk.

The application of labor market estimates of the VSL to value mortality risks from COVID-19 assumes that people are equally averse to these events. Occupational fatality risks that are captured in the risk measures in these studies are traumatic injuries that often lead to deaths that occur fairly soon after the traumatic event. There is an important morbidity component to the labor market VSL for these acute injuries, as estimated in Gentry and Viscusi (2016). Whether the morbidity effects of being killed in an occupational accident are greater or less than for COVID-19 is unclear. Another possible reference point that would boost benefit values is if COVID-19 morbidity effects were comparable to those associated with risks of cancer, for which there is often a prolonged morbidity period. Cancer risk studies generally show a premium for cancer risks as compared to traumatic risks, with the values being $21 \%$ greater for bladder cancer (Viscusi, Huber, and Bell 2014) than for mortality risks from motorvehicle accidents. The literature also includes premiums for other forms of cancer (e.g., see Van Houtven et al. 2008). There may or may not be a compelling rationale for adding a morbidity valuation premium to deaths from COVID-19, but it is important to recognize that equating mortality risks from COVID-19 to occupational fatality risks incorporates important benefit transfer assumptions including both the loss of one's life and the severity of the comparative health consequences of the fatal events. 


\section{Personalized values: Age and other personal characteristics}

\subsection{Life expectancy impacts}

The data in Table 1 covering the first half of 2020 indicate that the greatest number of deaths from COVID-19 is in the older age groups, particularly among those over age 55 , where the number of deaths begins to exceed 10,000. The number of COVID-19 deaths peaks among those age 85 and older, which accounts for one-third of all deaths. The age distribution of COVID-19 deaths is tilted toward a much more senior group than is reflected in studies of VSL in the labor market. The average age of workers in the VSL studies is age 40. Under 3\% of the COVID-19 deaths are for people at or below that age. This age difference between the labor market and COVID-19 victims is consequential since most VSL studies only estimate VSL figures for those who are in the principal pre-retirement years. Researchers generally cap the upper age of the sample at ages linked to social security benefit eligibility, such as limiting the sample to workers under age 62 or under age 65 . There is consequently a two decades' gap between the upper age limit for the VSL study estimates and the peak COVID-19 mortality group consisting of those age 85 or older. Given the age distribution of COVID-19 deaths, should the evaluation of the COVID-19 mortality risks use the average VSL for all workers in the policy assessment, following the usual practice of government agencies? Or should there be some recognition that individual willingness to pay for risk reduction is likely to vary with age? The quantity of remaining life has diminished with age, and available financial resources may differ as well.

Even if it is feasible to adjust the VSL for age, making age-related distinctions is likely to meet with considerable resistance among those in the affected age groups and also among those who have ethical reservations about valuing mortality risks to different population groups differently. Posing the question of whether there should be age variations in the VSL generates controversy, particularly when the heterogeneity in VSL results in the devaluation of life relative to the national average. Any reduction in the VSL for older people in effect takes something away from them that they had previously. The likely presence of an endowment effect with respect to the value the government places on their lives will be a source of opposition to such a devaluation. When the U.S. Environmental Protection Agency attempted to make adjustments for age in its regulatory impact analysis for the Clear Skies Initiative, there was substantial public outcry (Viscusi 2018b). Reducing the VSL for those over age 65 by $37 \%$ did not have a transparent justification and led to critiques such as "Seniors on sale, 37\% off" and "What's a Granny worth?" Whether one should embark on making such age adjustments depends on the magnitude of the life expectancy difference, the economic rationale for the adjustment, and the extent to which it is likely to be consequential. The view advocated here is that if there is recognition of the heterogeneity of the VSL, then it should be comprehensive and not restricted to age alone.

The statistics in Table 2 indicate the remaining life expectancy that is at risk for the average person in each age group. The peak remaining life expectancy is 77.1 years for the under age 5 group, and remaining life expectancy declines steadily with age. COVID-19 victims may have somewhat lower life expectancies than the population average to the extent that they have serious pre-existing conditions. Although there is some evidence that COVID-19 deaths are often accompanied by other adverse 
conditions before the death (Stokes et al. 2020), in the absence of available data to refine the life expectancy statistics I will rely on the average life expectancy figures in Table 2. COVID-19 incidence rates and life expectancy figures also can be constructed by gender, and these values appear as Appendix Table 5 . Men suffer greater mortality rates from COVID-19 than do women. For the average 40-year-old worker in VSL studies, the remaining life expectancy is an additional 40.7 years in the age group 3544. The remaining life expectancy continues to drop with age to a value of 6.6 years for the high-risk group of those age 85 and over. ${ }^{6}$

The expected number of life years lost statistics in Table 2 represent the expected number of life years lost to the individual in each age group. It is the product of the remaining life expectancy for that age group and the mortality risk to people in each age group from COVID-19, which appears in the final column in Table 1. Those who are age 85 and older suffer an expected number of life years lost equal to 0.04. Even for other age groups, the expected number of life years lost for members of each age group are not great because the probabilities of death from COVID-19 remain low. These statistics place the overall extent of the harm in context. What is pertinent from the standpoint of assessing benefits from reducing mortality risks is the loss that is being prevented conditional upon dying from the disease. For those who are age 85 or older, this loss is 6.6 years of life lost, which is still a substantial welfare loss.

\subsection{The value of a statistical life year (VSLY)}

Continuing to use the same average VSL for the economy for all those killed by COVID-19 is a straightforward, default benefit assessment approach. However, there are also two ways in which one might attempt to address potential age variations in mortality reduction benefits-i) using VSL estimates by age or ii) using estimates based on the value of a statistical life year (VSLY). Studies that have explored variations in the VSL with age using age-specific occupational fatality rates have generally found that the VSL exhibits an inverted-U shaped pattern with respect to age. The VSL in most labor market studies peaks in the 45-54 age group, where the estimated VSL exceeds the average for all workers. This is also the age range where the risk of death from COVID-19 begins to escalate. The VSL for older age groups declines from this peak, but even for workers in their early sixties the VSL typically remains higher than that of 24-year-olds. Unfortunately, labor market estimates of the VSL do not pertain to the three oldest age groups in Tables 1 and 2. Based on the data in Table 1,84\% of the COVID-19 deaths are among those in the age groups beginning at age 65 . Workers in the affected groups consequently are not typically included in labor market estimates of the VSL.

Monetizing small risks of death is feasible based on the value of a statistical life year (VSLY) implied by the VSL at different ages. Let L indicate the remaining life expectancy, and $\mathrm{r}$ be the rate of discount that people use in linking the VSL to the trajectory of VSLY values, which in this formula are assumed to have the same value per year. The theoretical relationship between the VSL and the VSLY introduced and first estimated in Moore and Viscusi (1988) is given by

\footnotetext{
${ }^{6}$ This life expectancy figure reflects the remaining life expectancy at age 85 , which will overstate the average remaining life expectancy of those over age 85 .
} 
Table 2 Life Expectancy Impacts of COVID-19 in the United States

\begin{tabular}{lll}
\hline Age group & Remaining life expectancy & Expected number of life years lost per person \\
\hline$<5$ & 77.1 & 0.0001 \\
$5-14$ & 69.2 & 0.0000 \\
$15-24$ & 59.4 & 0.0002 \\
$25-34$ & 50.0 & 0.0008 \\
$35-44$ & 40.7 & 0.0018 \\
$45-54$ & 31.6 & 0.0041 \\
$55-64$ & 23.3 & 0.0072 \\
$65-74$ & 15.7 & 0.0112 \\
$75-84$ & 9.2 & 0.0172 \\
$\geq 85$ & 6.6 & 0.0403 \\
\hline
\end{tabular}

Notes: Data reflect deaths in the United States from February 1, 2020 to June 20, 2020, updated on June 24. CDC (2020): https://data.cdc.gov/NCHS/Provisional-COVID-19-Death-Counts-by-Sex-Age-and-S/9bhghcku

Life Expectancy data are from Arias and Xu (2019):

https://www.cdc.gov/nchs/data/nvsr/nvsr68/nvsr68_07-508.pdf

$$
V S L Y=\frac{r V S L}{1-(1+r)^{-L}}
$$

Because of the shorter remaining life expectancy in older age groups, even if the VSLY has a constant value, the VSL for older individuals constructed using the VSLY will be less. The evidence regarding the VSLY indicates that these values are substantial, even for older worker groups. Although there have been numerous studies estimating the VSLY, those that are most reliable are those that use the CFOI mortality risk data conditional on worker age. Aldy and Viscusi (2008) match to each worker in the sample the mortality risk based on the worker's age and industry group. They find an average VSLY of $\$ 438,000$ in the basic regression estimates and $\$ 447,000$ in the cohort-adjusted estimates, where these values are in \$2019. In their analysis, the VSLY is not a constant, but instead is estimated as an average value for each worker age group. The VSLY peaks at $\$ 593,000$ at age 54 in the regular regressions and at a value of $\$ 555,000$ at age 45 in the cohort-adjusted estimates. The age-related trajectory of the cohort-adjusted VSLY for older age groups remains relatively flat after the peak, as it declines by just over $10 \%$ from the peak for those age 62 . The estimates reported by Viscusi and Hersch (2008) match risk to each worker in the sample based on age, industry, and gender. They find a rising pattern of VSLY with age for a sample that includes workers under age 65 . The average estimated VSLY for men is $\$ 578,000$, and the average VSLY for women is $\$ 414,000$ in $\$ 2019$. Weighting men and women equally yields an average VSLY of $\$ 496,000$ in $\$ 2019$.

For simplicity of calculations, suppose that the VSLY used to construct a VSL based on the lost life expectancy and the VSLY is $\$ 500,000$. By way of comparison, this value is similar to the figures for an expected life year used by the U.S. Department of Health and 
Human Services. ${ }^{7}$ If there is no discounting of the VSLY figures for years of life being valued, then the constructed VSL is simply the product of the VSLY and the number of years of remaining life expectancy. Using a zero discount rate that in effects weights the VSLY for all years of life equally, the constructed VSL is $\$ 3.3$ million for those at least age $85, \$ 4.6$ million for those age $75-84, \$ 7.9$ million for those $65-74$, and $\$ 11.7$ million for those 55-64, which I will cap at the economy-wide value of $\$ 11$ million in the calculations below. Discounting the sum of the VSLY amounts for the remaining life reduces these amounts, but they still remain substantial. Based on the $3 \%$ real rate of interest used in calculating the VSLY, the constructed VSL is $\$ 3.0$ million for those age 85 and above. For those age 75-84, the constructed VSL is $\$ 4.1$ million. The constructed VSL for the age 6574 age group is $\$ 6.4$ million, and the VSL is $\$ 8.5$ million for those age 55-64. For the other age groups, I make no reduction in the VSL below the average economy-wide VSL.

To consider the implications of these VSL figures by age for the average VSL for those affected by COVID-19, consider the distribution of the deaths shown in Table 1. Let the VSL applied to all deaths below age 55 be $\$ 11$ million, and the VSL for those in the other age groups be given by the estimates above. Weighting the VSL for each age group by their percentage of total COVID-19 deaths, the average economy-wide VSL based on the VSLY estimates is $\$ 6.1$ million using a zero discount rate to calculate the VSLY, or $45 \%$ below the $\$ 11$ million value, and $\$ 5.2$ million using a $3 \%$ discount rate to calculate the VSLY, which is $53 \%$ below the $\$ 11$ million value. Shifting from use of a single economy-wide VSL to an age-adjusted VSL constructed based on estimates of the VSLY in conjunction with remaining life expectancy reduces the applicable VSL by about half. The large extent of the reduction in the VSL is attributable to the skewed nature of the distribution of COVID-19 deaths, coupled with the level of the VSLY.

Being able to construct age-adjusted VSL estimates does not necessarily imply that policy makers should adopt these values for benefit-assessment purposes. From an equity standpoint, using the same VSL for all individuals is equitable in that it treats reduction of risks to all lives as being equally valuable. Moreover, given the widespread governmental practice of valuing mortality risks of all population segments equally except in a very few notable situations, using the average VSL for labor market risks is consistent with this practice. There also may be broadly based altruistic concerns with valuing all lives equally, as was reflected in the public outcry after the Clear Skies Initiative debacle. Alternatively, it is possible to provide an equity-based rationale for using a lower VSL that is constructed using the VSLY estimates. One can view using the same VSLY for everybody as being equitable in that each expected year of every person's life receives an equal weight. From the standpoint of efficient risk regulation, what matters is whether the individual WTP and WTA amounts for mortality risk reduction decline with age and, if so, to what extent. The age-adjusted estimates derived using the VSLY are more accurate reflections of the underlying WTP values of those affected. While the calculations below value mortality risks using an average VSL of \$11 million, it is straightforward to perform a sensitivity analysis on the results using the age-adjusted estimates derived from the VSLY. The back-of-the-envelope version of such a sensitivity analysis would be to divide the mortality risk reduction benefits by half, which will still yield very substantial benefits given the magnitude of the mortality risks.

\footnotetext{
7 The value of an expected quality-adjusted life year in \$2014 is \$490,000 based on a VSL of \$9.6 million and using a 3\% interest rate, which is $\$ 536,000$ in $\$ 2019$. See the U.S. Department of Health and Human Services (2016), p. 21.
} 


\subsection{Gender, race, income, and other personal characteristics}

While age has been a prominent personal characteristic with respect to coronavirus disease risks impacts, the risks of disease vary with other characteristics as well. Men suffer a greater risk than do women. As the data through June 20, 2020 in Appendix Table 4 indicate, there were 57,748 male deaths from COVID-19, or a mortality rate of 0.0363. Females fare somewhat better, with a total number of deaths in the same time period equal to 50,246 and a mortality rate of 0.0304 . Men have a shorter life expectancy than women so that for any given fatality their lost future lifetime is less, but they also have higher income levels, which boosts their gender-specific VSL. Risks vary by race as well. Although non-Hispanic whites comprise $60.4 \%$ of the population, they account for $53.2 \%$ of the deaths. As a group, non-Hispanic whites have been comparatively less affected by the pandemic. Hispanic or Latino death rate percentages also are a bit more favorable than their population percentage, as they also are for Asians, Native Americans, and other races. The hardest hit group consists of non-Hispanic blacks and AfricanAmericans, who account for $23 \%$ of the COVID-19 deaths despite comprising only $12.5 \%$ of the population. ${ }^{8}$ Given that the average income of black and African American workers is below that of the average worker, should there be an income elasticity adjustment to reduce the average VSL applied to the average victim of this pandemic?

This issue resurfaces in other guises as well. The individuals who have had the greatest exposures to the risk often are workers in industries that have been deemed "essential," such as transportation, food processing, supermarkets, mail and package delivery, and sanitation. Many white-collar jobs can be done remotely with less exposure, so that on balance workers in these jobs have been less affected. These essential workers also may incur greater risks to the extent that they rely on public transportation. Inequities also arise for the poor who lack excellent medical care and are at greater risk. The combination of influences such as race, occupation, and inadequate health care tend to tilt the distribution of COVID-19 risks and mortality rates toward segments of the population that have lower income levels. To the extent that the income levels of those affected are below those of the average worker in VSL studies, one can make an income elasticity adjustment using a United States VSL income elasticity value of 0.6. Thus, a 10\% income level below the population average reduces the applicable VSL by $6 \%$.

The fundamental ethical issue that affects both income and life expectancy adjustments is whether it is appropriate and desirable to depart from an average VSL for the economy to personalize the valuation to reflect the preferences and economic resources of those most affected by the risk. There are many concepts of risk equity that one might advocate. One might wish to give preference to the disadvantaged or victims of discrimination. Or one might view equitable risks in terms of providing the same upper bound on risk levels for all or perhaps a common level of risk reduction.

The equity concept that is often most reasonable is what I have termed "equitable risk tradeoffs" (Viscusi 2018). Across different policy arenas, equitable risk tradeoffs establish the same cost-risk tradeoff for all policies irrespective of the affected group. There may, of course, be desirable exceptions to using equitable risk tradeoffs as the

\footnotetext{
${ }^{8}$ Data reflect deaths in the United States from February 1, 2020 to June 20, 2020, updated on June 24, from the Centers for Disease Control (2020): https://data.cdc.gov/NCHS/Provisional-Death-Counts-forCoronavirus-Disease-C/pj7m-y5uh.
} 
policy guideline. For example, if airline passengers are paying for safety measures through higher ticket prices, then airline safety regulations that reflect their higher VSL levels may be desirable. In the case of COVID-19 policies, the policies are national in scope and are not self-financed by those affected. The equitable risk tradeoffs approach would suppress the devaluation of the lives of people with shorter remaining future lifetimes, lower income levels, high occupational risk exposures, and more limited access to health care. Instead, an equitable tradeoff rate would value risks to all lives equally using an average economy-wide VSL.

The policy ramifications of equitable risk tradeoffs may be consistent with widely held, but not fully articulated beliefs. Discussions of the plight of COVID-19 illnesses among those in essential industries or who have poor health care options usually reflect sympathy for their situation rather than a desire to provide them with less risk protection because we value risks to their lives less. If one were to design policies using a lower VSL because the victims have shorter life expectancy or are poorer, the result will be more deaths among these groups. Recognition of societal concern with these deaths would be consistent with the impetus of equitable risk tradeoffs. The outcry elicited by the devaluation of older lives in the Clear Skies Initiative analysis and the reluctance of government agencies to ever apply different VSL levels across income groups likewise may reflect the underlying equity concerns that are advanced by an equitable risk tradeoffs approach.

Equalizing the VSL for all affected groups implicitly provides a subsidy to the poor and those with shorter life expectancies. Although application of the VSL is usually viewed as an efficiency-oriented approach, adoption of an average economy-wide VSL that does not reflect the valuations of those being protected represents a departure from strict efficiency guidelines in that it incorporates equity concerns. Analysts preferring a strict efficiency-oriented approach can do so using the VSL estimates that account for differences in age and income using the adjustments discussed above.

\section{The worldwide mortality cost of COVID-19}

The most reliable worldwide VSL estimates are those that are based on the estimated VSL in the U.S., coupled with an income elasticity of 1.0 to adjust the VSL to other countries. There may of course be other differences across countries in risk preferences in addition to those stemming from income levels, but the income difference adjustments provide a consistent basis across countries for putting the VSL on a common basis. The income elasticity adjustment amount is consistent with both stated preference study evidence across countries as well as revealed preference evidence in labor market studies. Other available VSL figures for specific countries are more limited and do not provide a comprehensive perspective to address the large list of countries in Appendix Table 6.

Column 4 of Appendix Table 6 provides information on the VSL levels, and the second column lists the COVID-19 deaths for each country. The countries appear in order based on the number of positive COVID-19 tests. The United States is at the top of the list, as it accounts for $26 \%$ of the cases worldwide and $25 \%$ of the deaths. The U.S. VSL is also the highest figure other than the VSL at a small number of outliers, such as Qatar and Bermuda. With the exception of Brazil, which has a VSL of \$2.9 million, the VSL levels for the leading countries in terms of positive COVID-19 test results are quite substantial. The country-specific VSL is $\$ 7.8$ million in the U.K., \$7.2 million in Italy, \$8.0 million in 
France, \$6.7 million in Spain, and \$9.4 million in Germany. The highly successful coronavirus efforts in New Zealand took place in a country with a VSL of \$6.9 million.

The third column in Appendix Table 6 presents the total mortality costs from COVID19 in each country. The U.S. loss is the greatest value in the table, as it reflects both the large number of deaths and the relatively high VSL. The $\$ 1.4$ trillion mortality cost represents a huge loss to the United States. This single country's COVID-19 fatalities comprise $41 \%$ of the total worldwide mortality cost of $\$ 3.5$ trillion. There are five countries with a mortality cost of at least $\$ 100$ billion: U.K. at $\$ 343$ billion, Italy at $\$ 246$ billion, France at $\$ 237$ billion, Spain at \$189 billion, and Brazil at \$175 billion. Countries with effective COVID-19 policies are at the low end of mortality costs. Prominent countries with mortality costs under $\$ 1$ billion include New Zealand at $\$ 152$ million and Australia at $\$ 901$ million. There is enormous disparity worldwide in terms of the adverse health impacts of COVID-19.

Despite the daunting level of the health loss impacts, the general public often exhibits complacency with respect to efforts to reduce the impact of pandemics. The survey results reported by Pike et al. (2020) for a U.S. sample found that there was substantial undervaluation of risks to life from the standpoint of taking anticipatory preventive actions with respect to the West African Ebola outbreak. After the risk had reached the United States, the stated valuation of the risks did not reflect the major upward shift that the researchers anticipated. Consistent with this pattern, efforts to address the COVID-19 pandemic after it has begun have also been more modest than would have been expected in countries such as the United States. As indicated in Bruine de Bruin, Saw, and Goldman (2020), the politicization of the protective responses has hindered efforts to control the pandemic.

\section{Morbidity consequences}

COVID-19 illnesses cause morbidity effects as well as mortality effects. In the case of those who die from COVID-19 there may be associated pain and suffering that creates a welfare loss to the individual. As was discussed in Section 3, if these morbidity losses are more severe than those of occupational deaths, then it would be desirable to add a premium to the VSL. The focus of the discussion in this section is on the morbidity effects of those who do not die. The statistics in Table 3 indicate that just over 5\% of all laboratory-confirmed COVID-19 patients die. The 95\% of other patients who do not die constitute a much larger group. As a consequence, the morbidity effects that are experienced by those who do not die may affect the overall monetization of the benefits of reducing COVID-19 risks. In the absence of empirical estimates of the WTP values specifically associated with COVID-19, the benefit assessment approach must rely on the transfer of benefit values for risks of health consequences of comparable severity. The focus here is on morbidity risk estimates for similar environmental illnesses and the morbidity component of fatal job accidents. Kniesner and Sullivan (2020) explore a different benefit transfer reference point than the used here, focusing on the implicit value attached to nonfatal job injury risks and also taking into account the potential undercounting of the morbidity effects.

The adverse health impacts of COVID-19 often are severe for some patients. The most fortunate among those who have tested positive are those who are asymptomatic. These people may experience some anxiety with respect to their risk of developing 
additional symptoms, and there also may be broader anxiety effects for society at large from fear of contracting the disease (Stokes et al. 2020). For patients reporting symptoms, $70 \%$ experience fever, cough, or shortness of breath. An additional $36 \%$ experience muscle aches, and 34\% experience headaches. Some of the symptoms are quite serious and entail use of a ventilator to assist in being able to breathe. The statistics in Table 3 indicate that $14.0 \%$ of those with positive tests are hospitalized, and $2.3 \%$ are admitted to the ICU. The overlap among these categories is not clear since the data do not indicate whether or the extent to which the hospitalized or ICU patients also are included among the deaths. As is also the case with the death statistics, there is a strong age-related variation in hospital and ICU treatments. About one-third of all those age 70 and above who have positive test results are hospitalized.

To assess the unit benefit values that are appropriate for valuing morbidity effects that are not severe, consider stated preference values associated with health impacts that are comparable in severity. Studies of the benefits associated with the control of asthma also address respiratory issues, though these may understate the health impacts of the less consequential COVID-19 morbidity effects. O'Conor and Blomquist (1997) found an annual value of controlling asthma equal to $\$ 2200$ per year for adults, based on a $\$ 9$ million VSL. In $\$ 2019$, this loss would be about $\$ 3700$ per year. In a subsequent study, Blomquist, Dickie, and O'Connor (2011) estimated a value of asthma control of $\$ 1700$ for adults in their fifties and sixties, or \$2000 in \$2019. Suppose that for the purposes of valuing these minor health effects that one adopts a unit benefit value of $\$ 3000$. Consider the $82 \%$ of the patients with positive test results but who are not asymptomatic, hospitalized, or dead. Application of these benefit values to the total number of positive test cases in Table 3 would generate a benefit value of $(0.82) \times(1,320,488) \times$ $\$ 3000=\$ 3.3$ billion. This amount has a value comparable to preventing 295 deaths if each fatality is valued at $\$ 11$ million. By way of comparison, the total value of preventing the deaths for the time period indicated in Table 3 is $\$ 784$ billion, where this figure pertains to a shorter time period than the data in Appendix Table 6 . Consideration of the minor health impacts resulting from COVID-19 increases the benefit assessment by $0.4 \%$.

Table 3 Outcomes for Laboratory-Confirmed COVID-19 Patients

\begin{tabular}{lllll}
\hline Age group & Number of positive tests & Hospitalization $\%$ & ICU admission \% & Deaths \% \\
\hline$\leq 9$ & 20,458 & 4.1 & 0.7 & 0.1 \\
$10-19$ & 49,245 & 2.5 & 0.4 & 0.1 \\
$20-29$ & 182,469 & 3.7 & 0.5 & 0.1 \\
$30-39$ & 214,849 & 5.9 & 0.9 & 0.4 \\
$40-49$ & 219,139 & 8.8 & 1.5 & 1.0 \\
$50-59$ & 235,774 & 13.4 & 2.5 & 2.4 \\
$60-69$ & 179,007 & 22.0 & 4.1 & 6.7 \\
$70-79$ & 105,252 & 34.1 & 5.6 & 16.6 \\
$\geq 80$ & 114,295 & 32.5 & 3.6 & 28.7 \\
Total & $1,320,488$ & 14.0 & 2.3 & 5.4 \\
\hline
\end{tabular}

Source: Stokes et al. (2020), Table 3, January 22-May 30, 2020 
The more serious morbidity consequences are less frequent, but have a much greater unit benefit value. Suppose that all those who are reported as dead in Table 3 were originally hospitalized. Of the 185,673 hospitalized patients, 71,116 died, and 113,557 patients who were hospitalized did not die. By assuming that all deaths occurred after being hospitalized, this procedure understates the number of nonfatal hospital admissions due to COVID-19. To establish a unit benefit value for the morbidity effects of nonfatal hospitalizations, I draw on two different benefit transfer reference points, one of which is based on stated preference valuations and the other is drawn from estimates of the morbidity component of fatal job injuries. Each of these approaches generates large benefit numbers that increase the importance of preventing coronavirus illnesses.

The stated preference estimate of the morbidity component is based on the valuation of the risk of chronic bronchitis (Viscusi, Magat, and Huber 1991). The symptoms of this ailment as described to the survey respondents included uncomfortable shortness of breath, becoming easily winded when climbing stairs, coughing and wheezing regularly, and more frequent chest infections. Although some of the symptoms associated with the ailment may have long-term impacts, that also appears to be the case with COVID-19. U.S. Environmental Protection Agency regulatory impact analyses for proposed regulations have frequently used this unit benefits measure to value diverse risks of respiratory ailments caused by air pollution exposures. The study used a risk-risk tradeoff formulation in which respondents on average evaluated a case of chronic bronchitis as tantamount to a 0.32 probability of death. Based on an $\$ 11$ million VSL, the value of the nonfatal COVID-19 morbidity component is $0.32 \times \$ 11$ million $=\$ 3.4$ million.

An alternative perspective for valuing the morbidity effects of hospitalized COVID-19 patients is provided by the morbidity component of VSL for fatal job accidents estimated in Gentry and Viscusi (2016). The VSL is comprised of the value associated with the risk of incurring morbidity effects as a consequence of the fatal event, plus the value associated with the risk of terminating one's life. The labor market estimates of the VSL are based on traumatic occupational fatalities, most of which have a short period of morbidity. Overall, $82 \%$ of all fatally injured workers die within a day. Almost all fatally injured workers die within 3 months of the incident. The morbidity component of these injuries ranges from $6 \%$ to $25 \%$ of the VSL. The upper end of this range is below the chronic bronchitis value frequently used to value adverse respiratory effects. Because the COVID-19 hospitalizations have a longer duration than a single day, it may be reasonable to adopt the $25 \%$ estimate of the job-related morbidity value, leading to a morbidity effect of $0.25 \times \$ 11$ million $=\$ 2.75$ million. For the 113,557 nonfatal hospitalized patients in Table 3, the value of the morbidity loss is $\$ 312$ billion. Even at the lower end of the morbidity value estimate, the loss is substantial. Based on the $6 \%$ estimate of the occupational fatality morbidity share of the VSL, the morbidity cost per expected hospitalization with COVID19 is $0.06 \times \$ 11$ million $=\$ 0.66$ million. Using this lower figure, the value of the morbidity loss for the 113,557 hospitalized patients who do not die is $\$ 74.9$ billion.

The components of the health effect losses in Table 3 includes $\$ 784$ billion in mortality losses and $\$ 3$ billion in minor morbidity effects. For the upper estimate of the cost of serious morbidity effects, there is $\$ 312$ billion in more serious morbidity consequences, leading to a total health loss of $\$ 1.099$ trillion, which is $40 \%$ greater than the health impacts estimated by the mortality impact component alone. Applying the lower bound estimate of $6 \%$, which is likely to understate the loss, produces a total mortality and morbidity loss of $\$ 862$ billion, which is $10 \%$ greater than the value of the mortality effects alone. 
The morbidity effects have an additional pertinent feature in that they result in a more immediate loss in welfare than the mortality effects. Consideration of life expectancy differences will reduce that applicable VSL. But the life expectancy differences by age do not have a comparable impact on the more short-term morbidity effects. As a consequence, if the analysis uses age-adjusted VSL estimates, the inclusion of the morbidity effect benefits increases total benefits by $20 \%-80 \%$.

\section{Conclusion}

The monetized value of the health risk costs imposed by the COVID-19 pandemic are considerable. The mortality cost in the United States as of July 2, 2020 was over $\$ 1.4$ trillion. The mortality risk worldwide is $\$ 3.5$ trillion based on income-adjusted VSL estimates for these countries. These mortality cost amounts assume that the VSL that is applicable to the population in general is also pertinent to valuing the risks of COVID-19. Undertaking an age adjustment based on the current incidence rate would reduce the mortality costs by almost half. Making such an adjustment would be inconsistent with typical applications of the VSL in regulatory analyses, which generally use a uniform value. However, with over $80 \%$ of the COVID-19 deaths occurring among those who are age 65 or over, discussions of using age-adjusted VSL levels have increased. Attempts to devalue the COVID-19 deaths through age adjustments are likely to meet substantial resistance, as in the case of past efforts to adopt a "senior discount" for the VSL.

Comprehensive and consistent personalization of the VSL will lead to additional modifications of the VSL. Attempts to reflect the heterogeneity of the VSL should not be selective and restricted to age adjustments alone. COVID-19 also has a disproportionate impact on lower income groups, those with poor medical care, and African Americans. If the lives of older people are being devalued because they have lower personal valuations of risk, then a consistent valuation approach would also devalue the lives of the groups who are among the most vulnerable to COVID-19. At the very least, before embarking on any VSL adjustments for age there should be recognition that age differences are not the only pertinent source of VSL heterogeneity. Application of equity concepts such as an equitable risk tradeoffs approach would retain the economywide VSL for COVID-19, but there are other reasonable equity concepts or strict efficiency concepts that some might advance. For a wide diversity of different criteria, it is feasible to monetize these risks using the unit benefit estimates in this article.

Although the principal focus of the COVID-19 statistics has been on the total number of deaths, most people who have tested positive do not die. Mortality risks are the most highly valued health risks resulting from COVID-19, but the valuation of the morbidity risks is also quite substantial. Many people suffer these morbidity effects, which often are minor but sometimes are sufficiently severe to require hospitalization. Extrapolation based on other morbidity studies suggests that taking into account the morbidity losses boosts the total estimated value of the health risks by perhaps as much as $40 \%$, and certainly accounts for at least a lower bound increase of $10 \%$. Further studies could refine the morbidity benefit values, but regardless it is clear that the morbidity consequences of this pandemic are quite substantial as well. To the extent that analysts choose to use a lower age-adjusted VSL, the relative contribution of morbidity effects to the total benefit value will be enhanced. 
Much of the focus of the coronavirus discussions has been on the economic costs associated with disruptions to the economy, chiefly arising from efforts to contain the pandemic. Not all of the costs during the economic downturn are attributable to the precautionary efforts. The economic trajectory would have been adversely affected by the illnesses even if there were no lockdown efforts. The dichotomy between the economic costs of the pandemic and the health impacts is not a valid distinction. The health risk losses associated with COVID-19 can be monetized to be in the same units as the cost of disruptions to the economy. The mortality and morbidity effects of COVID-19 are very real and substantial economic losses.

\section{Appendix}

Table 4 The Age Distribution of COVID-19 Deaths in the United States

\begin{tabular}{|c|c|c|c|}
\hline \multicolumn{4}{|c|}{ Panel A: Males } \\
\hline Age group & Number of deaths & Percentage of all male deaths & Deaths per 100 population \\
\hline$<5$ & 8 & 0.014 & 0.00008 \\
\hline $5-14$ & 11 & 0.019 & 0.00005 \\
\hline $15-24$ & 85 & 0.147 & 0.00040 \\
\hline $25-34$ & 496 & 0.859 & 0.00218 \\
\hline $35-44$ & 1327 & 2.298 & 0.00655 \\
\hline $45-54$ & 3678 & 6.369 & 0.01846 \\
\hline $55-64$ & 8516 & 14.747 & 0.04287 \\
\hline $65-74$ & 13,893 & 24.058 & 0.09331 \\
\hline $75-84$ & 15,717 & 27.217 & 0.23278 \\
\hline $85+$ & 14,017 & 24.273 & 0.61424 \\
\hline All ages & 57,748 & 100 & 0.03631 \\
\hline \multicolumn{4}{|c|}{ Panel B: Females } \\
\hline Age group & Number of deaths & Percentage of all female deaths & Deaths per 100 population \\
\hline$<5$ & 7 & 0.014 & 0.00007 \\
\hline $5-14$ & 2 & 0.004 & 0.00001 \\
\hline $15-24$ & 47 & 0.094 & 0.00023 \\
\hline $25-34$ & 236 & 0.470 & 0.00105 \\
\hline $35-44$ & 533 & 1.061 & 0.00257 \\
\hline $45-54$ & 1560 & 3.105 & 0.00751 \\
\hline $55-64$ & 4379 & 8.715 & 0.02000 \\
\hline $65-74$ & 8536 & 16.988 & 0.05143 \\
\hline $75-84$ & 13,017 & 25.907 & 0.15038 \\
\hline $85+$ & 21,929 & 43.643 & 0.60728 \\
\hline All ages & 50,246 & 100 & 0.03039 \\
\hline
\end{tabular}

Notes: Data reflect deaths in the United States from February 1, 2020 to June 20, 2020, updated on June 24. CDC (2020a and b): https://data.cdc.gov/NCHS/Provisional-COVID-19-Death-Counts-by-Sex-Age-and-S/ 9bhg-hcku .

The 2019 age group population data are from the U.S. Census Bureau (2020):

https://www.census.gov/data/tables/2019/demo/age-and-sex/2019-age-sex-composition.html . 
Table 5 Life Expectancy Impacts of COVID-19 in the United States

\begin{tabular}{|c|c|c|}
\hline Age group & Remaining life expectancy & Expected number of life years lost per person \\
\hline \multicolumn{3}{|c|}{ Panel A: Males } \\
\hline$<5$ & 74.6 & 0.0001 \\
\hline $5-14$ & 66.7 & 0.0000 \\
\hline $15-24$ & 57.0 & 0.0002 \\
\hline $25-34$ & 47.8 & 0.0010 \\
\hline $35-44$ & 38.7 & 0.0025 \\
\hline $45-54$ & 29.8 & 0.0055 \\
\hline $55-64$ & 21.7 & 0.0093 \\
\hline $65-74$ & 14.5 & 0.0135 \\
\hline $75-84$ & 8.4 & 0.0196 \\
\hline$\geq 85$ & 5.9 & 0.0362 \\
\hline \multicolumn{3}{|c|}{ Panel B: Females } \\
\hline$<5$ & 79.6 & 0.0001 \\
\hline $5-14$ & 71.6 & 0.0000 \\
\hline $15-24$ & 61.8 & 0.0001 \\
\hline $25-34$ & 52.1 & 0.0005 \\
\hline $35-44$ & 42.6 & 0.0011 \\
\hline $45-54$ & 33.4 & 0.0025 \\
\hline $55-64$ & 24.7 & 0.0049 \\
\hline $65-74$ & 16.7 & 0.0086 \\
\hline $75-84$ & 9.8 & 0.0147 \\
\hline$\geq 85$ & 7.0 & 0.0425 \\
\hline
\end{tabular}

Notes: Data reflect deaths in the United States from February 1, 2020 to June 20, 2020, updated on June 24. CDC (2020a and b): https://data.cdc.gov/NCHS/Provisional-COVID-19-Death-Counts-by-Sex-Age-and-S/ 9bhg-hcku.

Life Expectancy data are from Arias and Xu (2019):

https://www.cdc.gov/nchs/data/nvsr/nvsr68/nvsr68_07-508.pdf. 
Table 6 The Global Mortality Costs of COVID-19

\begin{tabular}{|c|c|c|c|}
\hline Country & Number of Deaths & VSL x Deaths (\$ millions) & VSL (\$ millions) \\
\hline Total & 519,399 & $3,479,110$ & \\
\hline United States & 130,813 & $1,438,943$ & 11 \\
\hline Brazil & 60,813 & 174,995 & 2.8776 \\
\hline Russia & 9683 & 44,001 & 4.5441 \\
\hline India & 17,860 & 20,589 & 1.1528 \\
\hline United Kingdom & 43,906 & 343,292 & 7.8188 \\
\hline Spain & 28,363 & 189,130 & 6.6682 \\
\hline Peru & 9860 & 22,733 & 2.3056 \\
\hline Chile & 5753 & 25,035 & 4.3516 \\
\hline Italy & 34,788 & 246,285 & 7.0796 \\
\hline Iran & 11,106 & 38,727 & 3.487 \\
\hline Mexico & 28,510 & 91,888 & 3.223 \\
\hline Pakistan & 4473 & 4551 & 1.0175 \\
\hline Turkey & 5150 & 19,437 & 3.7741 \\
\hline Saudi Arabia & 1752 & 18,368 & 10.4841 \\
\hline Germany & 9061 & 85,029 & 9.3841 \\
\hline France & 29,861 & 237,944 & 7.9684 \\
\hline South Africa & 2749 & 6764 & 2.4607 \\
\hline Bangladesh & 1926 & 1311 & 0.6809 \\
\hline Canada & 8615 & 72,296 & 8.3919 \\
\hline Colombia & 3470 & 8989 & 2.5905 \\
\hline Qatar & 118 & 3124 & 26.4737 \\
\hline China & 4636 & 12,754 & 2.7511 \\
\hline Egypt & 3034 & 6211 & 2.0471 \\
\hline Sweden & 5370 & 49,997 & 9.3104 \\
\hline Argentina & 1363 & 5215 & 3.8258 \\
\hline Belarus & 405 & 1310 & 3.2351 \\
\hline Belgium & 9761 & 85,199 & 8.7285 \\
\hline Indonesia & 2987 & 6111 & 2.046 \\
\hline Ecuador & 4576 & 9861 & 2.1549 \\
\hline Iraq & 2160 & 6334 & 2.9326 \\
\hline Netherlands & 6113 & 57,742 & 9.4457 \\
\hline United Arab Emirates & 316 & 4230 & 13.3859 \\
\hline Kuwait & 359 & 5790 & 16.1271 \\
\hline Ukraine & 1185 & 1777 & 1.4993 \\
\hline Singapore & 26 & 404 & 15.554 \\
\hline Kazakhstan & 188 & 844 & 4.4891 \\
\hline Oman & 188 & 1389 & 7.3887 \\
\hline Portugal & 1579 & 8771 & 5.555 \\
\hline Philippines & 1274 & 2178 & 1.7094 \\
\hline Poland & 1492 & 7395 & 4.9566 \\
\hline Panama & 645 & 2523 & 3.9116 \\
\hline
\end{tabular}


Table 6 (continued)

\begin{tabular}{|c|c|c|c|}
\hline Country & Number of Deaths & VSL $x$ Deaths ( $\$$ millions) & VSL (\$ millions) \\
\hline Bolivia & 1201 & 1540 & 1.2826 \\
\hline Dominican Republic & 754 & 1961 & 2.6004 \\
\hline Afghanistan & 807 & 299 & 0.3707 \\
\hline Switzerland & 1965 & 24,079 & 12.254 \\
\hline Romania & 1687 & 6970 & 4.1316 \\
\hline Bahrain & 93 & 687 & 7.3909 \\
\hline Armenia & 459 & 769 & 1.6764 \\
\hline Nigeria & 603 & 670 & 1.111 \\
\hline Israel & 324 & 2232 & 6.8893 \\
\hline Ireland & 1738 & 18,145 & 10.4401 \\
\hline Honduras & 542 & 492 & 0.9086 \\
\hline Guatemala & 817 & 1176 & 1.4399 \\
\hline Japan & 974 & 7878 & 8.0883 \\
\hline Ghana & 117 & 91 & 0.7799 \\
\hline Azerbaijan & 220 & 722 & 3.2824 \\
\hline Austria & 705 & 6626 & 9.3984 \\
\hline Moldova & 549 & 566 & 1.0318 \\
\hline Serbia & 287 & 736 & 2.5652 \\
\hline Nepal & 31 & 15 & 0.4774 \\
\hline Algeria & 920 & 2517 & 2.7357 \\
\hline Korea, Rep. & 282 & 1877 & 6.655 \\
\hline Morocco & 228 & 335 & 1.4696 \\
\hline Denmark & 606 & 5705 & 9.4138 \\
\hline Cameroon & 313 & 184 & 0.5874 \\
\hline Czech Republic & 349 & 2105 & 6.0313 \\
\hline Cote d'Ivoire & 68 & 42 & 0.6237 \\
\hline Sudan & 602 & 459 & 0.7623 \\
\hline Uzbekistan & 27 & 32 & 1.1858 \\
\hline Norway & 251 & 3140 & 12.5081 \\
\hline Malaysia & 121 & 606 & 5.0072 \\
\hline Australia & 104 & 901 & 8.6636 \\
\hline Finland & 328 & 2671 & 8.1444 \\
\hline Congo, Dem. Rep. & 176 & 24 & 0.1375 \\
\hline Senegal & 121 & 55 & 0.4554 \\
\hline El Salvador & 191 & 301 & 1.5752 \\
\hline Kenya & 149 & 88 & 0.5874 \\
\hline North Macedonia & 306 & 803 & 2.6246 \\
\hline Kyrgyzstan & 66 & 42 & 0.6325 \\
\hline Venezuela & 54 & 174 & 3.2285 \\
\hline Haiti & 107 & 36 & 0.3366 \\
\hline Tajikistan & 52 & 34 & 0.6611 \\
\hline Ethiopia & 103 & 32 & 0.3102 \\
\hline
\end{tabular}


Table 6 (continued)

\begin{tabular}{|c|c|c|c|}
\hline Country & Number of Deaths & VSL $x$ Deaths ( $\$$ millions) & VSL (\$ millions) \\
\hline Gabon & 42 & 152 & 3.6091 \\
\hline Guinea & 33 & 7 & 0.2145 \\
\hline Bulgaria & 232 & 793 & 3.4177 \\
\hline Mauritania & 129 & 94 & 0.726 \\
\hline Bosnia and Herzegovina & 189 & 394 & 2.0834 \\
\hline Luxembourg & 110 & 1516 & 13.7797 \\
\hline Hungary & 587 & 2833 & 4.8257 \\
\hline CAR & 47 & 6 & 0.1188 \\
\hline Costa Rica & 17 & 48 & 2.8501 \\
\hline Greece & 192 & 974 & 5.0721 \\
\hline Thailand & 58 & 172 & 2.9667 \\
\hline West Bank and Gaza & 8 & 8 & 0.9691 \\
\hline Croatia & 110 & 471 & 4.2779 \\
\hline Albania & 69 & 149 & 2.1626 \\
\hline Nicaragua & 83 & 80 & 0.9669 \\
\hline Madagascar & 24 & 6 & 0.2695 \\
\hline Maldives & 10 & 22 & 2.1945 \\
\hline Cuba & 86 & 375 & 4.3637 \\
\hline Paraguay & 19 & 32 & 1.6599 \\
\hline Mali & 116 & 44 & 0.3762 \\
\hline Sri Lanka & 11 & 24 & 2.1989 \\
\hline South Sudan & 38 & 12 & 0.3113 \\
\hline Equatorial Guinea & 32 & 166 & 5.1997 \\
\hline Estonia & 69 & 374 & 5.4274 \\
\hline Iceland & 10 & 90 & 9.0156 \\
\hline Lithuania & 78 & 411 & 5.2701 \\
\hline Lebanon & 35 & 92 & 2.629 \\
\hline Slovakia & 28 & 158 & 5.6276 \\
\hline Guinea-Bissau & 24 & 7 & 0.2772 \\
\hline Slovenia & 111 & 662 & 5.9609 \\
\hline Zambia & 30 & 21 & 0.6963 \\
\hline New Zealand & 22 & 152 & 6.9113 \\
\hline Sierra Leone & 60 & 18 & 0.2981 \\
\hline Congo, Rep. & 41 & 50 & 1.2078 \\
\hline Malawi & 16 & 3 & 0.2178 \\
\hline Cabo Verde & 15 & 18 & 1.2078 \\
\hline Hong Kong & 7 & 77 & 11.0616 \\
\hline Benin & 21 & 8 & 0.3916 \\
\hline Yemen & 318 & 165 & 0.5203 \\
\hline Tunisia & 50 & 106 & 2.1219 \\
\hline Jordan & 9 & 19 & 2.057 \\
\hline Latvia & 30 & 142 & 4.7487 \\
\hline
\end{tabular}


Table 6 (continued)

\begin{tabular}{|c|c|c|c|}
\hline Country & Number of Deaths & VSL $x$ Deaths ( $\$$ millions) & VSL (\$ millions) \\
\hline Niger & 67 & 12 & 0.1815 \\
\hline Rwanda & 3 & 1 & 0.3289 \\
\hline Cyprus & 19 & 115 & 6.0522 \\
\hline Burkina Faso & 53 & 17 & 0.3168 \\
\hline Uruguay & 28 & 109 & 3.8995 \\
\hline Georgia & 15 & 27 & 1.7853 \\
\hline Mozambique & 6 & 1 & 0.2233 \\
\hline Uganda & - & - & 0.3476 \\
\hline Chad & 74 & 30 & 0.4037 \\
\hline Liberia & 37 & 5 & 0.1375 \\
\hline São Tomé and Príncipe & 13 & 8 & 0.6215 \\
\hline Jamaica & 10 & 17 & 1.6599 \\
\hline Malta & 9 & 57 & 6.3415 \\
\hline Togo & 14 & 4 & 0.2541 \\
\hline Zimbabwe & 7 & 2 & 0.3267 \\
\hline Montenegro & 12 & 38 & 3.1471 \\
\hline Suriname & 13 & 41 & 3.1757 \\
\hline Tanzania & 21 & 11 & 0.5027 \\
\hline Vietnam & - & - & 1.0934 \\
\hline Mauritius & 10 & 38 & 3.8115 \\
\hline Myanmar & 6 & 6 & 0.9427 \\
\hline Comoros & 7 & 2 & 0.2849 \\
\hline Namibia & - & - & 1.9844 \\
\hline Angola & 15 & 19 & 1.2364 \\
\hline Guyana & 13 & 19 & 1.441 \\
\hline Botswana & 1 & 3 & 2.9656 \\
\hline Mongolia & - & - & 2.145 \\
\hline Eritrea & - & - & 0.3619 \\
\hline Burundi & 1 & 0 & 0.1397 \\
\hline Bermuda & 9 & 113 & 12.5664 \\
\hline Brunei & 3 & 47 & 15.7025 \\
\hline Cambodia & - & - & 0.6314 \\
\hline Trinidad and Tobago & 8 & 49 & 6.1523 \\
\hline Bahamas & 11 & 46 & 4.1998 \\
\hline Barbados & 7 & 21 & 2.9843 \\
\hline Seychelles & - & - & 4.9071 \\
\hline Bhutan & - & - & 1.4586 \\
\hline Antigua and Barbuda & 3 & 13 & 4.2592 \\
\hline Gambia & 2 & 1 & 0.2959 \\
\hline Macao & - & - & 19.591 \\
\hline Lesotho & - & - & 0.6292 \\
\hline St. Vincent Grenadines & - & - & 2.1197 \\
\hline
\end{tabular}


Table 6 (continued)

\begin{tabular}{llll}
\hline Country & Number of Deaths & VSL x Deaths (\$ millions) & VSL (\$ millions) \\
\hline Belize & 2 & 3 & 1.5334 \\
Timor-Leste & - & - & 0.8701 \\
Grenada & - & - & 2.5025 \\
Laos & - & - & 1.0318 \\
St. Lucia & - & - & 2.0603 \\
Dominica & - & - & 2.0075 \\
Fiji & - & - & 1.6918 \\
St. Kitts and Nevis & - & - & 4.6585 \\
Papua New Guinea & - & - & 0.5852 \\
\hline
\end{tabular}

Notes: VSL figures are based on Viscusi (2019), updated for inflation. Mortality figures are from Worldometer,

July 2, 2020: https:/web.archive.org/web/20200702133224/https://www.worldometers.info/coronavirus/. Countries appear in order based on the number of positive COVID-19 tests.

\section{References}

Aldy, J. E., \& Viscusi, W. K. (2008). Adjusting the value of a statistical life for age and cohort effects. Review of Economics and Statistics, 90(3), 573-581.

Arias, E., \& Xu, J. (2019). United States life tables, 2017. National Vital Statistics Reports, 68(7), 1-65.

Blomquist, G., Dickie, M., \& O’Connor, R. (2011). Willingness to pay for improving fatality risks and asthma symptoms: Values for children and adults of all ages. Resource and Energy Economics, 33(2), 410-425.

Bruine de Bruin, W., Saw, H.-W., \& Goldman, D. (2020). Political polarization in US residents' COVID-19 risk perceptions, policy preferences, and protective behaviors. Journal of Risk and Uncertainty, 61(2). https://doi.org/10.1007/s11166-020-09336-3.

Centers for Disease Control. (2020a). Provisional COVID-19 death counts by sex, age, and state. https://data. cdc.gov/NCHS/Provisional-COVID-19-Death-Counts-by-Sex-Age-and-S/9bhg-hcku. Accessed Jun 24, 2020.

Centers for Disease Control. (2020b). Provisional death counts for coronavirus disease (COVID-19): Weekly state-specific data updates. https://data.cdc.gov/NCHS/Provisional-Death-Counts-for-CoronavirusDisease-C/pj7m-y5uh. Accessed Jun 24, 2020.

Doucouliagos, H., Stanley, T. D., \& Viscusi, W. K. (2014). Publication selection and the income elasticity of the value of a statistical life. Journal of Health Economics, 33(1), 67-75.

Gentry, E. P., \& Viscusi, W. K. (2016). The fatality and morbidity component of the value of statistical life. Journal of Health Economics, 46(2), 90-99.

Greenstone, M., \& Nigam, V. (2020). Does social distancing matter? University of Chicago Becker Friedman Institute for Economics working paper, SSRN 3561244.

Hammitt, J. K. (2020). Valuing mortality risk in the time of COVID-19. Journal of Risk and Uncertainty, 61(2). https://doi.org/10.1007/s11166-020-09338-1.

Hammitt, J. K., \& Robinson, L. A. (2011). The income elasticity of the value per statistical life: Transferring estimates between high and low income populations. Journal of Benefit-Cost Analysis, 2(1), 1-29.

Kniesner, T. J., \& Sullivan, R. (2020). The forgotten numbers: A closer look at COVID-19 non-fatal valuations. Journal of Risk and Uncertainty, 61(2). https://doi.org/10.1007/s11166-020-09339-0. 
Kniesner, T. J., Viscusi, W. K., Woock, C., \& Ziliak, J. P. (2012). The value of a statistical life: Evidence from panel data. Review of Economics and Statistics, 94(1), 74-87.

Masterman, C. J., \& Viscusi, W. K. (2018). The income elasticity of global values of a statistical life: Stated preference evidence. Journal of Benefit-Cost Analysis, 9(3), 407-434.

Moore, M. J., \& Viscusi, W. K. (1988). The quantity-adjusted value of life. Economic Inquiry, 26(3), 369388.

O’Conor, R., \& Blomquist, G. (1997). Measurement of consumer-patient preferences using a hybrid contingent valuation method. Journal of Health Economics, 16(6), 667-683.

Pike, J., Shogren, J. F., Aadland, D., Viscusi, W. K., Finoff, D., Skiba, A., \& Daszak, P. (2020). Waking up to the reality of a pandemic. EcoHealth, 17, 217-221. https://doi.org/10.1007/s10393-020-01479-8. Accessed Jul 13, 2020.

Robinson, L., Sullivan, R., \& Shogren, J. F. (2020). Do the benefits of COVID-19 policies exceed the costs? Exploring uncertainties in the age-VSL relationship. Risk Analysis, https://doi.org/10.1111/risa.13561.

Stokes, E. K., Zambrano, L. D., Anderson, K. N., Marder, E. P., Raz, K. H., El Burai Felix, S., Tie, Y., \& Fullerton, K. E. (2020). Coronavirus disease 2019 case surveillance-United States, Jan. 22 - May 30, 2020. Morbidity and Mortality Weekly Report, 69, 759-765, https://doi.org/10.15585/mmwr.mm6924e2. Accessed Jul 13, 2020.

Stanley, T. D., \& Doucouliagos, H. (2012). Meta-regression analysis in economics and business. London: Routledge.

Thunstrom, L., Newbold, S., Finnoff, D., Ashworth, M., \& Shogren, J.F. (2020). The benefits and cost of flattening the curve for COVID-19. Journal of Benefit-Cost Analysis, 11(2), 1-17. https://doi.org/10. 1017/bca.2020.12. Accessed Jul 13, 2020.

U.S. Census Bureau. (2020). Age and sex composition in the United States. https://www.census.gov/data/ tables/2019/demo/age-and-sex/2019-age-sex-composition.html. Accessed Jun 24, 2020.

U.S. Department of Health and Human Services. (2016). Guidelines for regulatory impact analysis. https:// aspe.hhs.gov/system/files/pdf/242926/HHS_RIAGuidance.pdf. Accessed Jul 13, 2020.

U.S. Department of Transportation. (2016). Revised departmental guidance. Guidance on treatment of the economic value of statistical life (VSL) in U.S. Department of Transportation analyses - 2016 adjustment. https://cms7.dot.gov/office-policy/transportation-policy/revised-departmental-guidance-on-valuation-ofa-statistical-life-in-economic-analysis. Accessed Jul 13, 2020.

U.S. Environmental Protection Agency. (2016). Guidelines for preparing economic analyses. https://www.epa. gov/environmental-economics/guidelines-preparing-economic-analysis. Accessed Jul 13, 2020.

Van Houtven, G., Sullivan, M. B., \& Dockins, C. (2008). Cancer premiums and latency effects: A risk tradeoff approach for valuing reductions in fatal cancer risks. Journal of Risk and Uncertainty, 36(2), 179-199.

Viscusi, W. K. (2004). The value of life: Estimates with risks by occupation and industry. Economic Inquiry, $42(1), 29-48$.

Viscusi, W. K. (2010). Policy challenges of the heterogeneity of the value of a statistical life. Foundations and Trends in Microeconomics, 6(2), 99-172.

Viscusi, W. K. (2015). The role of publication selection bias in estimates of the value of a statistical life. American Journal of Health Economics, 1(1), 27-52.

Viscusi, W. K. (2018a). Best estimate selection bias in the value of a statistical life. Journal of Benefit-Cost Analysis, 9(2), 205-246.

Viscusi, W. K. (2018b). Pricing lives: Guideposts for a safer society. Princeton: Princeton University Press.

Viscusi, W. K. (2019). Risk guideposts for a safer society: Introduction and overview. Journal of Risk and Uncertainty, 58(2-3), 101-119.

Viscusi, W. K., \& Aldy, J. E. (2003). The value of a statistical life: A critical review of market estimates throughout the world. Journal of Risk and Uncertainty, 27(1), 5-76.

Viscusi, W. K., \& Hersch, J. (2008). The mortality cost to smokers. Journal of Health Economics, 27(4), 943958.

Viscusi, W. K., Huber, J., \& Bell, J. (2014). Assessing whether there is a cancer premium for the value of a statistical life. Health Economics, 23(4), 384-396.

Viscusi, W. K., Magat, W. A., \& Huber, J. (1991). Pricing environmental health risks: Survey assessments of risk-risk and risk-dollar trade-offs for chronic bronchitis. Journal of Environmental Economics and Management, 21(1), 32-51.

Viscusi, W. K., \& Masterman, C. J. (2017a). Anchoring biases in international estimates of the value of a statistical life. Journal of Risk and Uncertainty, 54(2), 103-128. 
Viscusi, W. K., \& Masterman, C. J. (2017b). Income elasticities and global values of a statistical life. Journal of Benefit-Cost Analysis, 8(2), 226-250.

Worldometer. (2020). COVID-19 Coronavirus Pandemic. https://web.archive.org/web/20200702133224/ https:/www.worldometers.info/coronavirus/. Accessed Jul 2, 2020.

Publisher's note Springer Nature remains neutral with regard to jurisdictional claims in published maps and institutional affiliations. 